\title{
Application of Ferrite Nanomaterial in RF On-Chip Inductors
}

\author{
Hua-Lin Cai, ${ }^{1,2}$ Jing Zhan, ${ }^{1,2}$ Chen Yang, ${ }^{1,2}$ Xiao Chen, ${ }^{1,2}$ Yi Yang, ${ }^{1,2}$ Bao-Yong Chi, ${ }^{1,2}$ \\ Albert Wang, ${ }^{3}$ and Tian-Ling Ren ${ }^{1,2}$ \\ ${ }^{1}$ Institute of Microelectronics, Tsinghua University, Beijing 100084, China \\ ${ }^{2}$ National Laboratory for Information and Science Technology, Tsinghua University, Beijing 100084, China \\ ${ }^{3}$ Department of Electrical Engineering, University of California, Riverside, CA 92521, USA
}

Correspondence should be addressed to Tian-Ling Ren; rentl@tsinghua.edu.cn

Received 26 April 2013; Accepted 23 May 2013

Academic Editor: Yang Chai

Copyright (C) 2013 Hua-Lin Cai et al. This is an open access article distributed under the Creative Commons Attribution License, which permits unrestricted use, distribution, and reproduction in any medium, provided the original work is properly cited.

\begin{abstract}
Several kinds of ferrite-integrated on-chip inductors are presented. Ferrite nanomaterial applied in RF on-chip inductors is prepared and analyzed to show the properties of high permeability, high ferromagnetic resonance frequency, high resistivity, and low loss, which has the potential that will improve the performance of RF on-chip inductors. Simulations of different coil and ferrite nanomaterial parameters, inductor structures, and surrounding structures are also conducted to achieve the trend of gains of inductance and quality factor of on-chip inductors. By integrating the prepared ferrite magnetic nanomaterial to the on-chip inductors with different structures, the measurement performances show an obvious improvement even in GHz frequency range. In addition, the studies of CMOS compatible process to integrate the nanomaterial promote the widespread application of magnetic nanomaterial in RF on-chip inductors.
\end{abstract}

\section{Introduction}

For decades the RF on-chip inductors have a large occupation of chip area and low $Q$ factor [1-4], it hindered the realization of high-performance RF circuits and systems. Nowadays, the situation becomes more and more serious, as the development of on-chip RF inductor cannot keep up with the pace of miniaturization of integrated circuit system [5]. There is an increasing demand for small-sized and high-performance RF on-chip inductors in CMOS circuits and systems. Many efforts are made to solve the problem, and the works about these are impressive. To improve the $Q$-factor, suspension and solenoid structure [6-9], thick insulating layer [10], grounded shield $[11,12]$, and high resistivity substrate structure $[2,13]$ are applied to reduce the substrate loss; coils made by high conductivity metal $[14,15]$ and low k interlayer dielectric [16] are applied to reduce the resistive loss; multilayer inductors are applied to reduce the area occupation $[17,18]$. However, all the previosely mentioned works cannot both satisfy the demands of small size and high $Q$ factor at the same time. Meanwhile most of them are not CMOS compatible.
Recently more and more attention is being paid to the integration of magnetic nanomaterial to the on-chip inductors, which can enhance the storage of magnetic energy and thus increase the inductance and reduce the area of on-chip inductors [19-21]. However, most of the adopted magnetic materials are ferromagnetic alloy [22-25], which lead to large magnetic loss and reduced $Q$ in high frequency due to its low ferromagnetic resonance $f_{\mathrm{FMR}}$. On the other hand, ferromagnetic alloy film must be isolated from the coils due to its low resistivity, which limits its magnetic flux enhancing effect. Other methods to improve the inductors' performance are also discussed in [26-31]. But most of these magnetic materials have their limitations. Compared with other materials, ferrite nanomaterial featured high $f_{\mathrm{FMR}}$, and low imaginary part of permeability $\mu^{\prime \prime}$ can improve the $Q$ factor of inductors in $\mathrm{GHz}$ range [32-36], which is expected to provide a perfect solution to this situation. Furthermore, nanostructure magnetic material also has high resistivity and hence is more likely to contact the coils directly and forms a fully filled magnetic structure [37-39], which will take advantage of magnetic flux enhancement effect in 


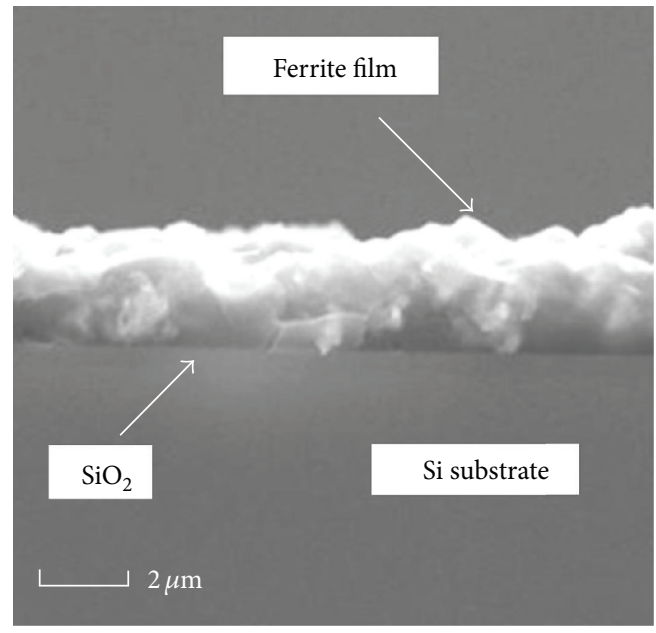

FIgURE 1: Ferrite nanomaterial film spin-coated on Si substrate.

the maximum degree. Application of the ferrite nanomaterial shows a great prospect in RF on-chip inductors [38-41].

\section{Materials}

Magnetic nanomaterial will exhibit superparamagnetic property when the diameter of the particle is small enough. This phenomenon weakens the hysteresis of the magnetic material, which is beneficial to the property of low loss that RF on-chip inductors require. Ferrite has high relative permeability, low magnetic loss, and high resistivity and therefore is suitable to be used for RF on-chip inductors in $\mathrm{GHz}$ working frequency. Among all the ferrite material, spinel and magnetoplumbite ferrite stand out. Nanomaterials of $\mathrm{Ni}-\mathrm{Zn}-\mathrm{Cu}$ spinel and $\mathrm{Co}_{2} \mathrm{Z}$ magnetoplumbite ferrite are mainly introduced with nanopowder-mixed-photoresist spin-coating and ink-jetting processes which are CMOScompatible [42-45].

$\mathrm{Ni}-\mathrm{Zn}-\mathrm{Cu}$ and $\mathrm{Co}_{2} \mathrm{Z}$ nanopowder are prepared through sol-gel material and self-progating method. The redox between nitrates and organic acids triggers self-propagating combustion when the sol-gel is heated to a certain temperature. The material preparation flow is shown below.

(1) Dissolve the compound in a citric acid solution, and keep the solution density at $0.2 \mathrm{~mol} / \mathrm{L}$.

(2) Heat the solution in an oven under a low temperature of $60^{\circ} \mathrm{C}$ for $48 \mathrm{~h}$ until the solution is transformed into a brown viscous gel.

(3) Heat the viscous on hot plate at $200^{\circ} \mathrm{C}$ to dry; then ignite it to burn completely.

(4) Ball-mill the remaining powders for over $72 \mathrm{~h}$ to get $\mathrm{Ni}-\mathrm{Zn}$-Cu nanoparticles of less than $100 \mathrm{~nm}$ diameter.

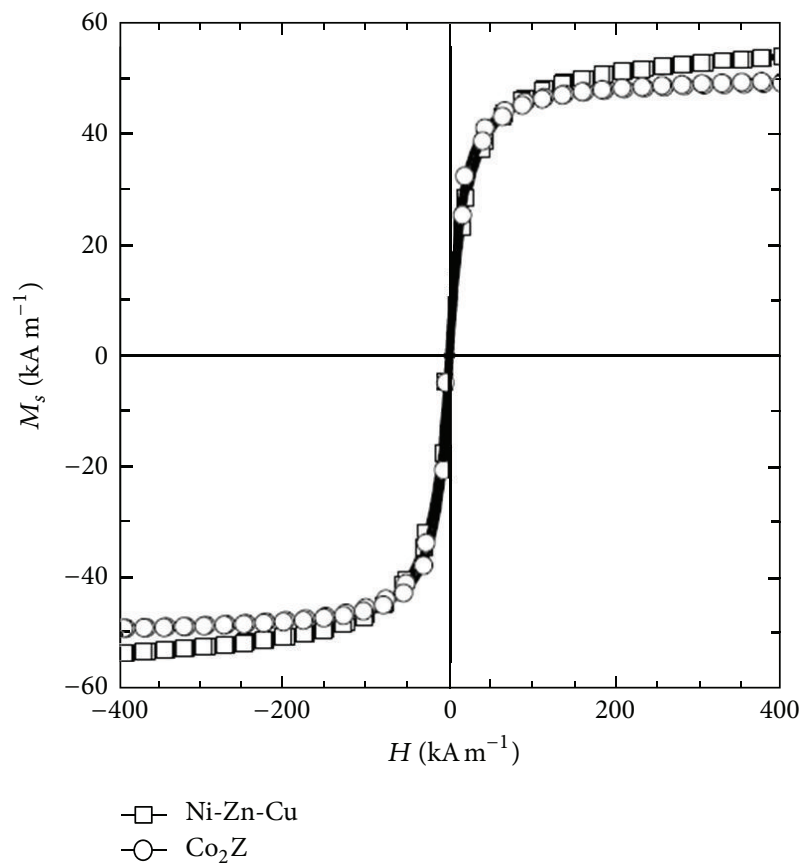

FIGURE 2: Hysteresis loops of $\mathrm{Ni}-\mathrm{Zn}-\mathrm{Cu}$ and $\mathrm{Co}_{2} \mathrm{Z}$.

$\mathrm{Co}_{2} \mathrm{Z}$ is prepared through solid reaction method, and the flow is shown below.

(1) Mix all the ingredients evenly in alcohol, and then put in $\mathrm{Al}_{2} \mathrm{O}_{3}$ crucible.

(2) Heat the mixture in $1270^{\circ} \mathrm{C}$ for $4 \mathrm{~h}$ during which the crystallization reaction proceed.

(3) Ball-mill the powders for over $72 \mathrm{~h}$ to get nanoparticles of less than $100 \mathrm{~nm}$ diameter.

After the ferrite nanoparticles are prepared, mix them in photoresist with a proper percentage to get the composite ferrite nanomaterial. Then two methods are developed to apply the as-fabricated ferrite nanomaterial on the inductors. The first one is spin-coating, followed by heating and solidifying at $120^{\circ} \mathrm{C}$ to obtain the film with certain thickness. Then the film is patterned through an extra photolithography and etching processes. The SEM photo of ferrite film spin-coated on the substrate is shown in Figure 1. The second method is inkjetting. It is carried out by a microprobe dropping nanomaterial at the place of inductor coil area.

The hysteresis loop of nanomaterial is shown in Figure 2. The prepared ferrite (mixed in photoresist) has a high saturation magnetization $\left(M_{s}=53 \mathrm{kA} / \mathrm{m}\right)$ compared with other ferrite materials, low remanent magnetization $\left(M_{r}=\right.$ $11.3 \mathrm{kA} / \mathrm{m})$, and low coercivity $\left(H_{c}=2.5 \mathrm{kA} / \mathrm{m}\right)$.

Ring-shaped samples are prepared for the high frequency permeability spectrum measurement sintered from the ferrite nanopowder. Figure 3 shows the high frequency spectrum. The magnetic spectrum of $\mathrm{Ni}-\mathrm{Zn}-\mathrm{Cu}$ and $\mathrm{Co}_{2} \mathrm{Z}$ shows a high permeability and low loss in RF range, which are suitable to apply to the RF on-chip inductors in GHz. 


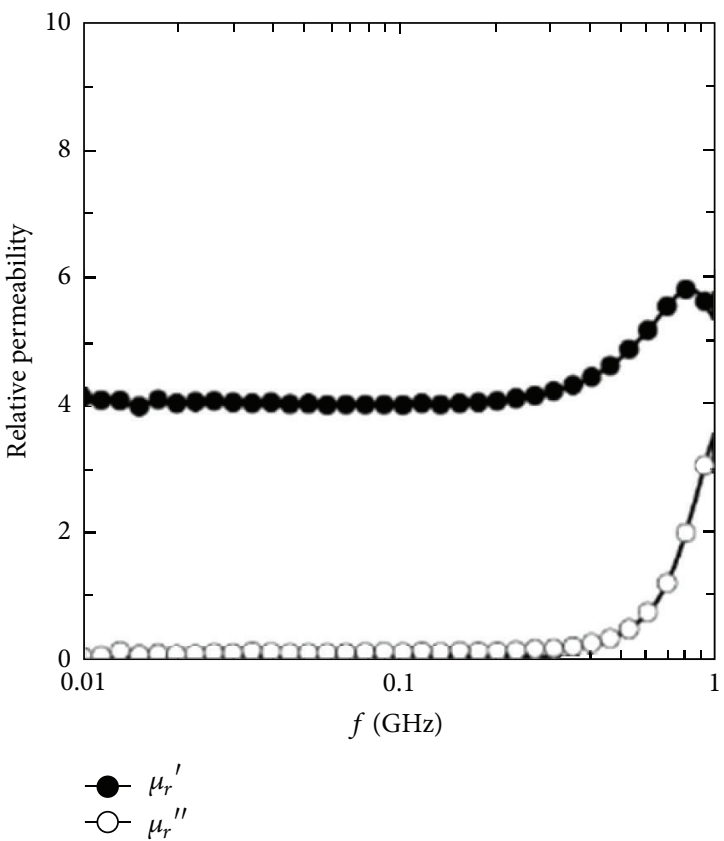

(a)

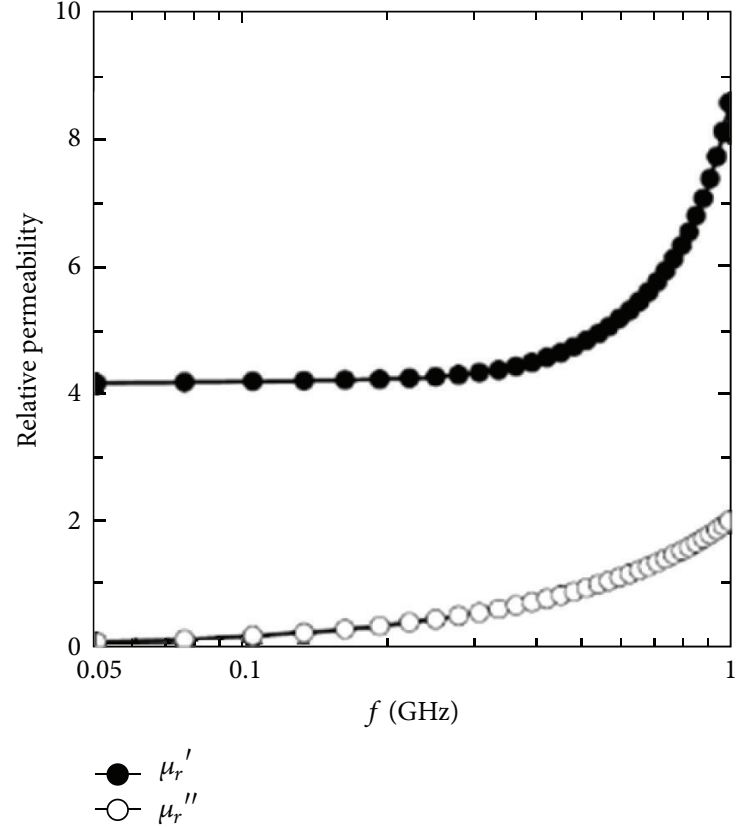

(b)

Figure 3: Magnetic spectrum of (a) Ni-Zn-Cu, (b) $\mathrm{Co}_{2} \mathrm{Z}$.

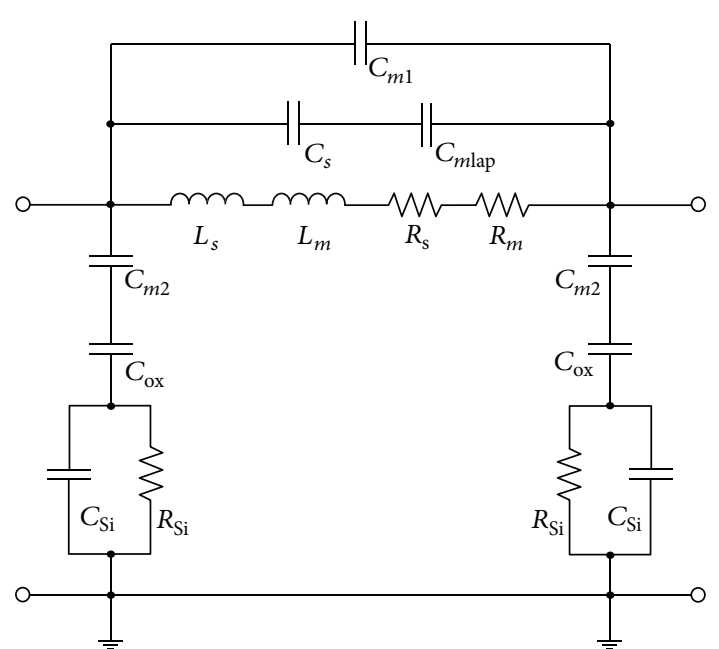

FIGURE 4: Equivalent circuit of on-chip magnetic inductors.

\section{Design}

The two-port $\Pi$ type equivalent circuit of on-chip magnetic inductors is shown in Figure 4.

$L_{s}$ and $R_{s}$ are the series inductance and resistance of the spiral coils respectively; $C_{s}$ is the feedback capacitance, which mainly results from the overlapping of adjacent coil layers; $C_{\mathrm{ox}}$ is the equivalent silicon dioxide insulation layer capacitance of one port; $C_{\mathrm{Si}}$ and $R_{\mathrm{Si}}$ are the equivalent substrate capacitance and resistance, respectively; to describe the physical influence of the integration of magnetic material, some parameters are added based on the original equivalent model. $L_{m}$ is the gain of $L_{s}$ due to the real part of permeability $\mu^{\prime} ; R_{m}$ is the gain of $R_{s}$ due to the imaginary part of permeability $\mu^{\prime \prime} ; C_{\text {mlap }}$ describes the series capacitance change of $C_{s}$ when the magnetic material is integrated; $C_{m 1}$ is the added capacitance between coils; $C_{m 2}$ is the added equivalent capacitance results from the ferrite between the bottom coil layer and the silicon dioxide insulation layer [46-49].

Several structures of ferrite nanomaterial integrated inductors are designed, which are shown in Figure 5. Structures (a)-(d) are single layer on-chip inductors with different magnetic structures. Structure (a) is an air-cored reference without magnetic nanomaterial; structure (b) has underlaiferrite film; structure (c) has ferrite film coated on the top, and structure (d) has a fully filled ferrite. Structures (e)(h) are stacked multilayer inductors with different magnetic structure, where structure (e) has ferrite film coated on the top; structure (f) has ferrite sandwiched; structure (g) has ferrite sandwiched and cored, and structure (h) has ferrite fully filled. Structure (i) is a solenoid inductor with fully filled ferrite.

Simulation works are carried out utilizing Ansoft HFSS to investigate the influence of various structures, permeability, and substrate resistivity on the performance enhancement compared to the corresponding air-cored reference [50]. 


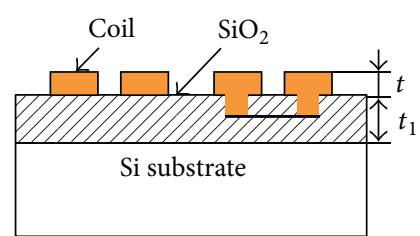

(a)

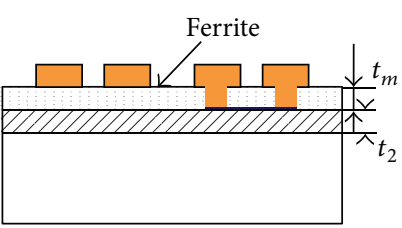

(b)

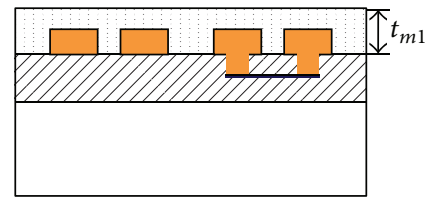

(c)

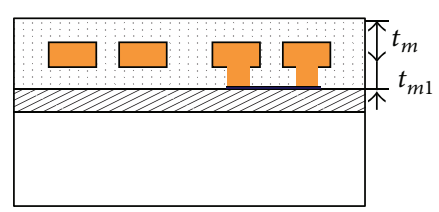

(d)

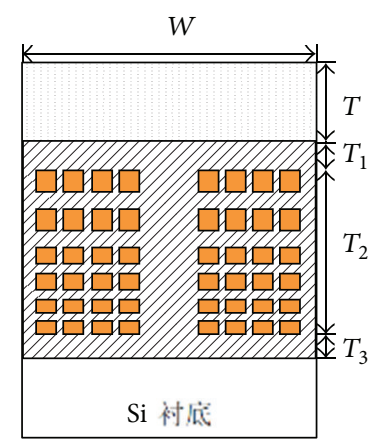

(e)

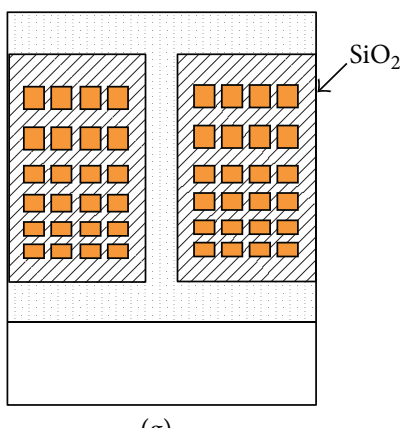

(g)

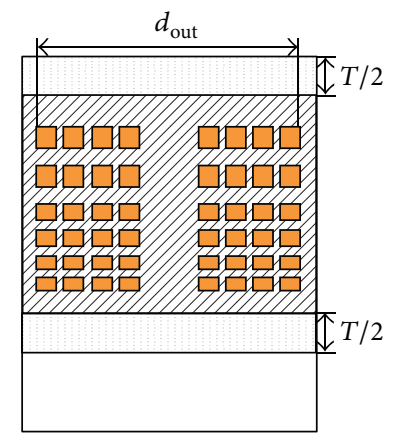

(f)

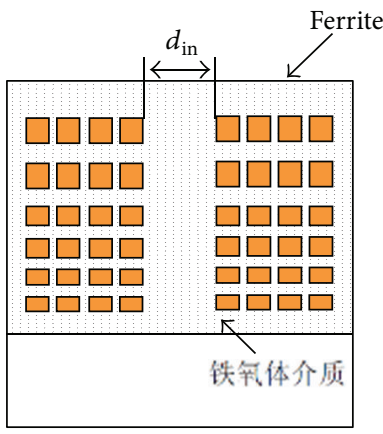

(h)
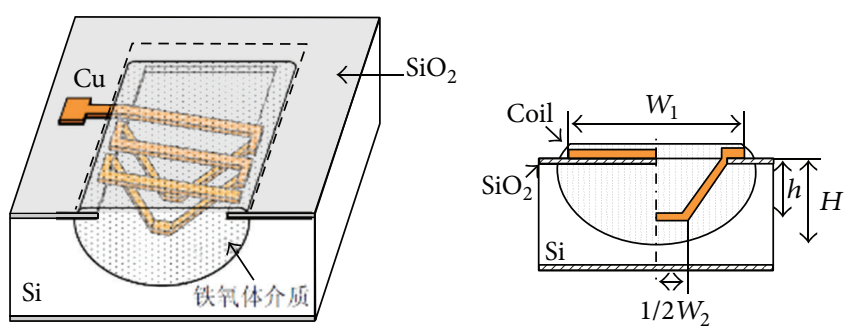

(i)

FIGURE 5: Different types of on-chip magnetic inductors.

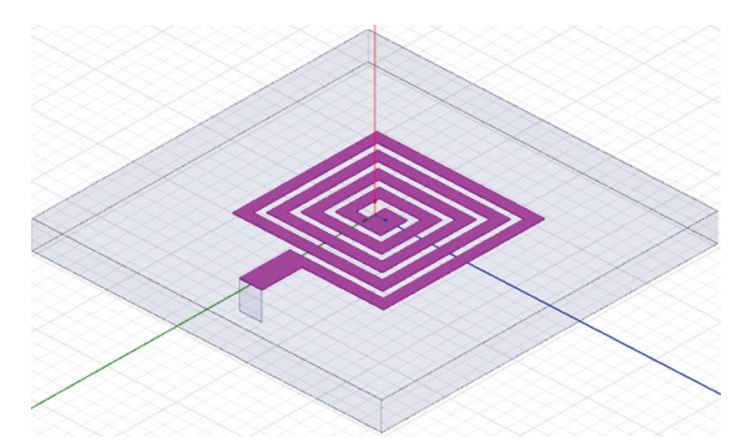

FIGURE 6: Simulation of spiral inductor in HFSS environment.

A typical 4-turn inductor in simulation environment is shown in Figure 6.
Figure 7 compares the $L$ and $Q$ of structures $B, C$, and D with $\mu^{\prime}=10$, as well as the reference structure $A$. It can be observed that from structure B to structure $D$, the inductance of on-chip inductors has an increasing trend. Structure D has the largest gain in $Q$, while structure $C$ has a limited gain in $Q$, and its $Q$ reduces largely in high frequency. The results show that structure $D$ with fully filled ferrite has the best improvement in both $L$ and $Q$ among structure B to D while the ferrite is ideal.

Figure 8 shows the influence of different relative permeability on $L$ and $Q$. When the permeability increases from 5 to 10 , the improvement of both $L$ and $Q$ factor increases greatly for structure D. It can be seen that structure D with $\mu^{\prime}=5$ has a better improvement than structure B with $\mu^{\prime}=10$, which proves again that the fully filled ferrite magnetic structure has the best performance.

Substrate loss is one of the main reasons for the limitation of $Q$ factor of on-chip inductors. Figure 9 shows the impact 


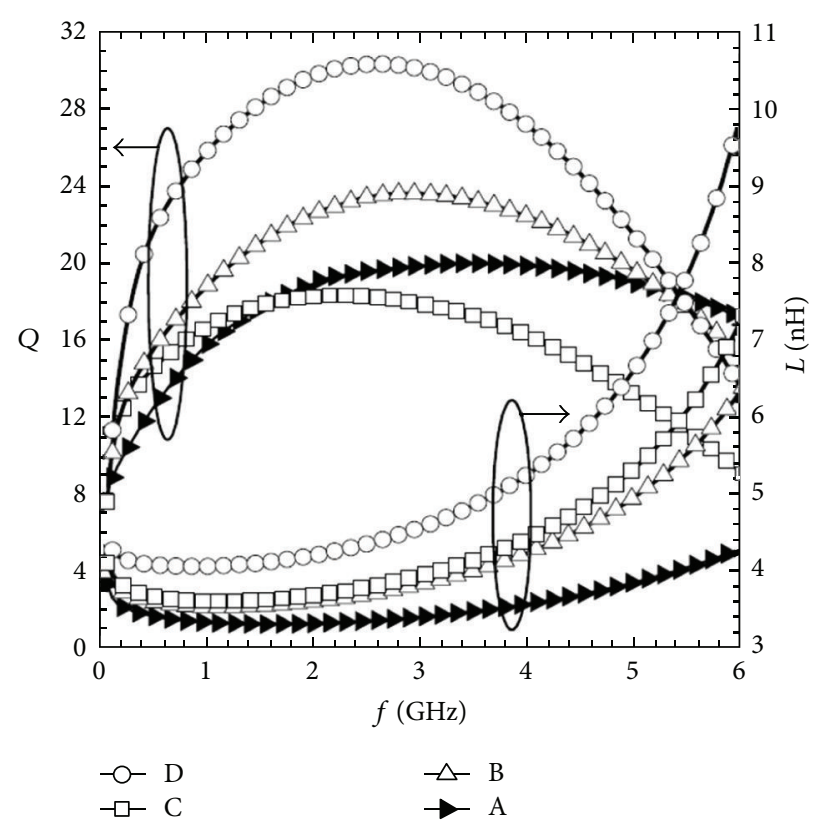

FIgURE 7: $L$ and $Q$ of single layer inductors with different magnetic structures.

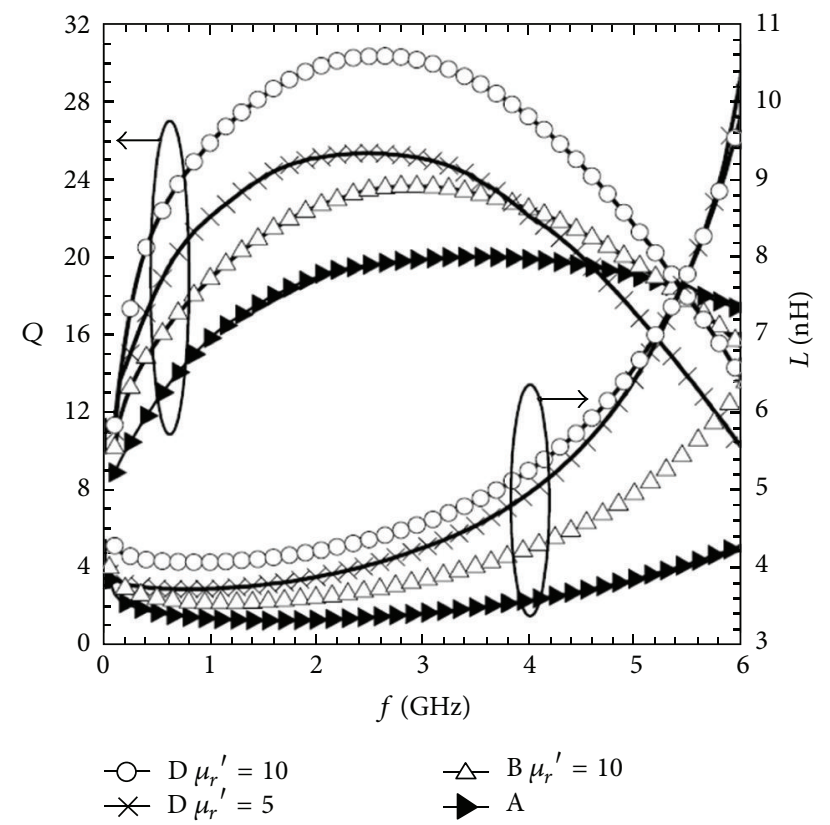

Figure 8: $L$ and $Q$ of single layer inductors under different relative permeability.

of different substrate resistivity on inductors' performance with substrate resistivity increasing from $100 \mathrm{ohm} \cdot \mathrm{cm}$ to $2000 \mathrm{ohm} \cdot \mathrm{cm}$; the substrate eddy loss reduces, and hence the $Q$ factor of on-chip inductors is improved obviously, while the $L$ changes little.

The turns of on-chip inductors, coil space, and width are also designed to have an optimization result.

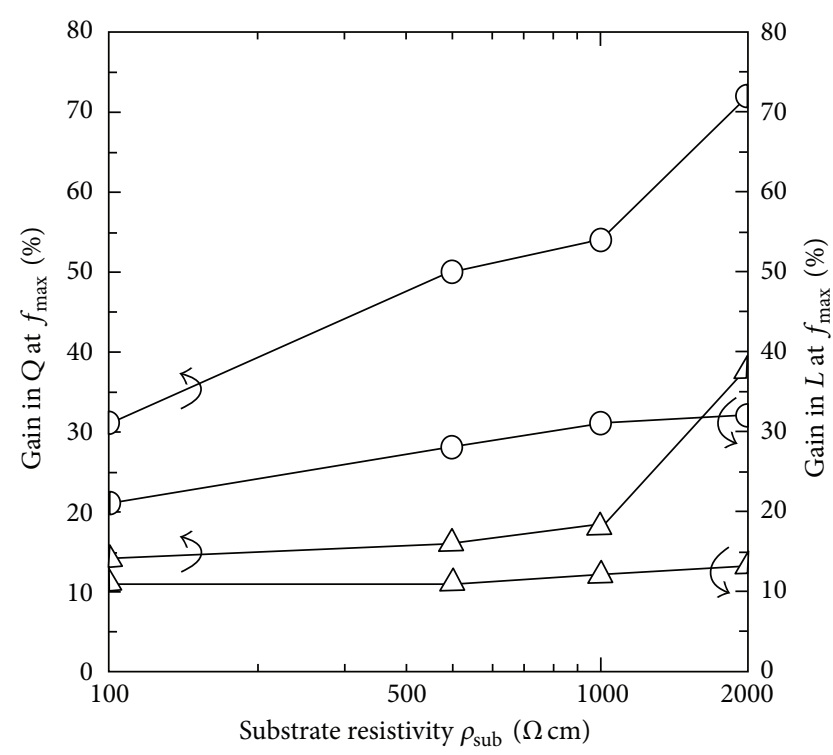

$-\mathrm{O}-\mathrm{D}$

$-\triangle B$

FIGURE 9: $L$ and $Q$ of single layer inductors with different substrate resistivity.

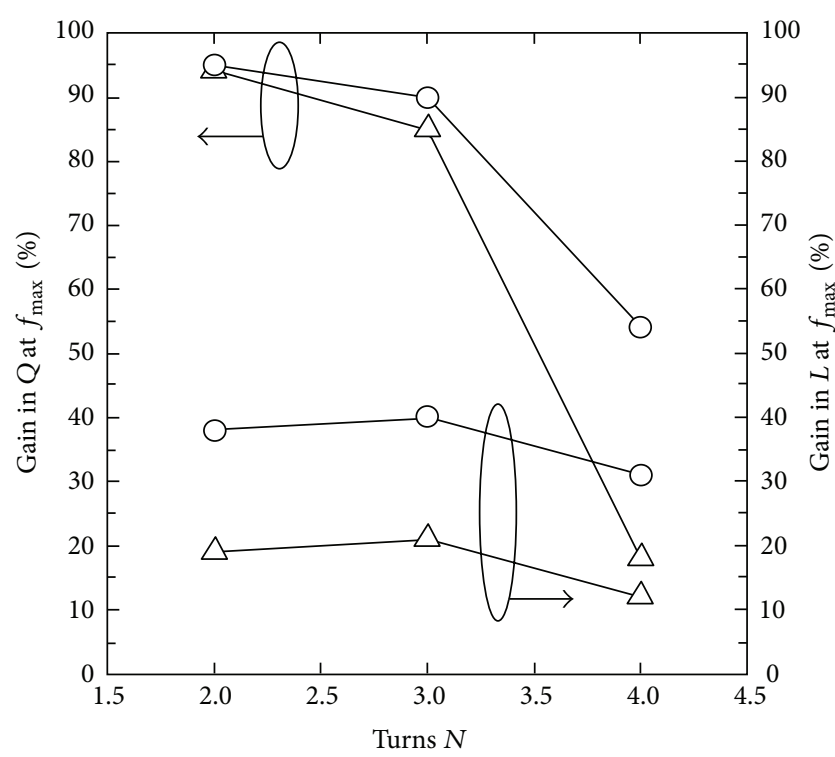

$-\mathrm{O}-\mathrm{D}$

$\triangle B$

Figure 10: $L$ and $Q$ increment with different turns.

In Figure 10, with the turns of spiral increase from 2 to 4 , the gain in $L$ and $Q$ factor shows a decrease trend, and the reason is that the more turns of coils result in a more eddy current loss in the substrate.

In Figure 11, with the width of spiral increase from 10 to 30 , the gain in $L$ and $Q$ factor remains nearly the same to structure $\mathrm{D}$; the gain in $Q$ varies a little, and the gain in $L$ 


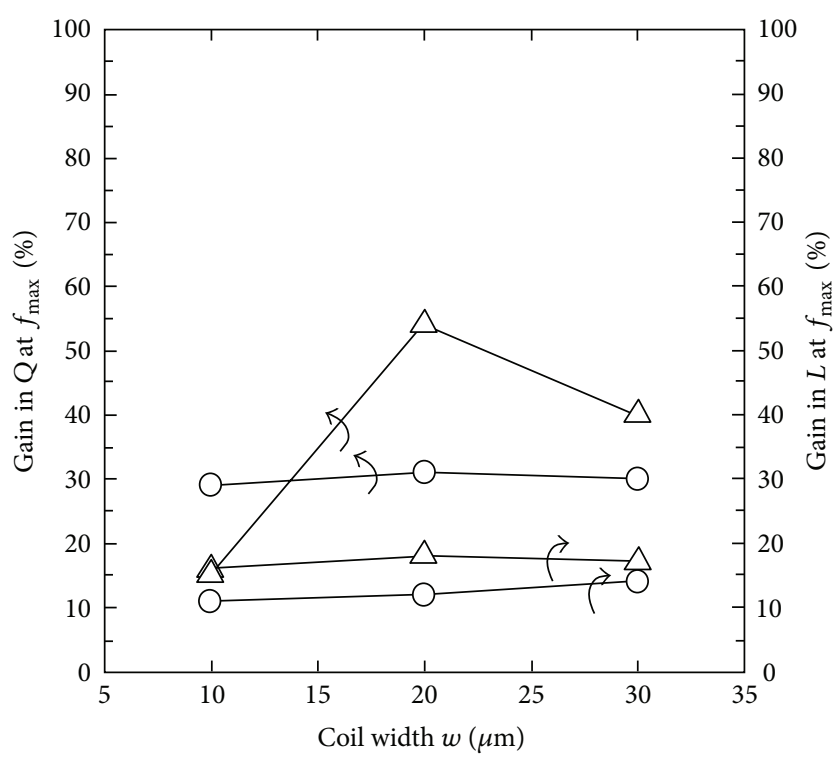

$-\mathrm{O}-\mathrm{D}$

$-\triangle \mathrm{B}$

FIGURE 11: $L$ and $Q$ of single layer inductors with different coil width.

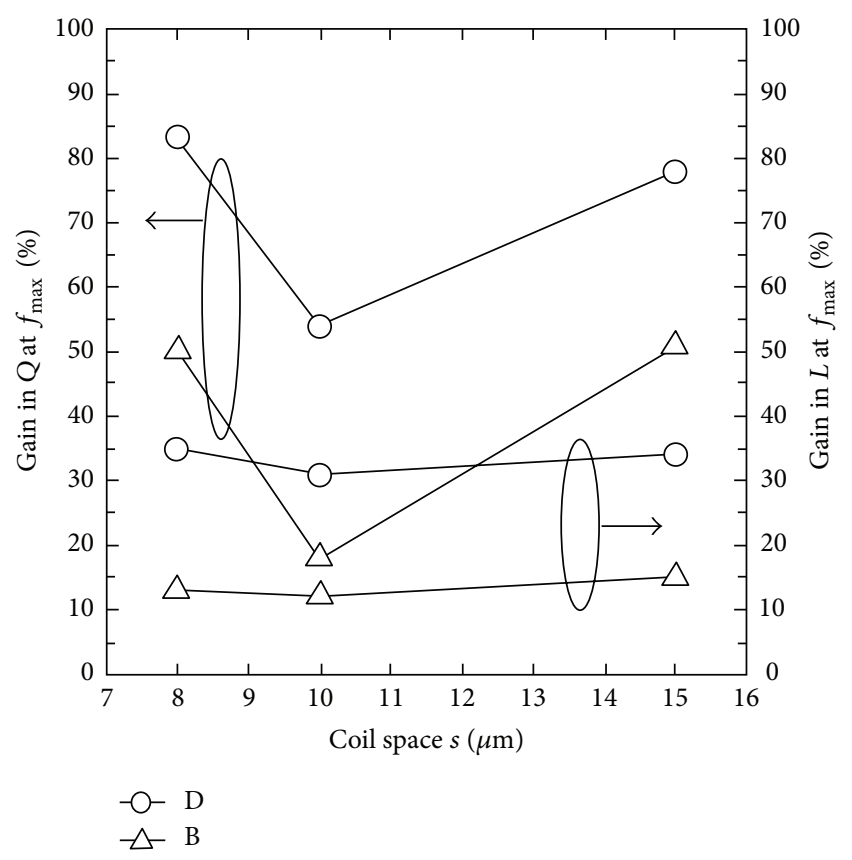

Figure 12: $L$ and $Q$ increment with different coil space.

reaches the highest point with a width of $20 \mathrm{um}$ to structure B.

In Figure 12, with the coil space of spiral increase from 8 to 15 , the gain in $L$ changes a little and the gain in $Q$ have the poorest performance improvement with a coil space of $10 \mathrm{um}$ to structure B and D.

For multilayer and solenoid on-chip inductors, the performance improvement of structure E-H i discussed, which is shown in Figure 13. With the relative permeability of on-chip

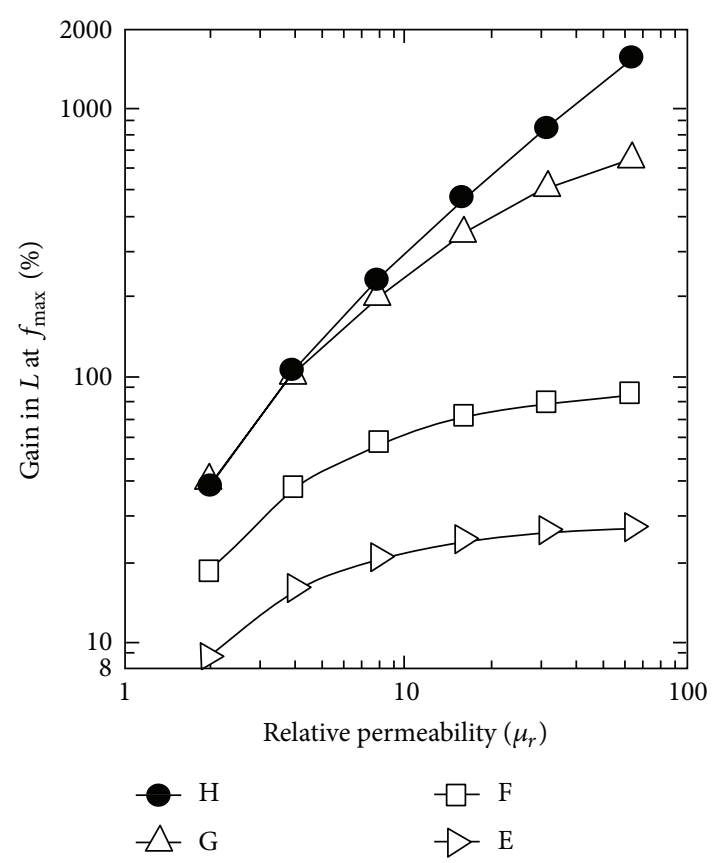

(a)

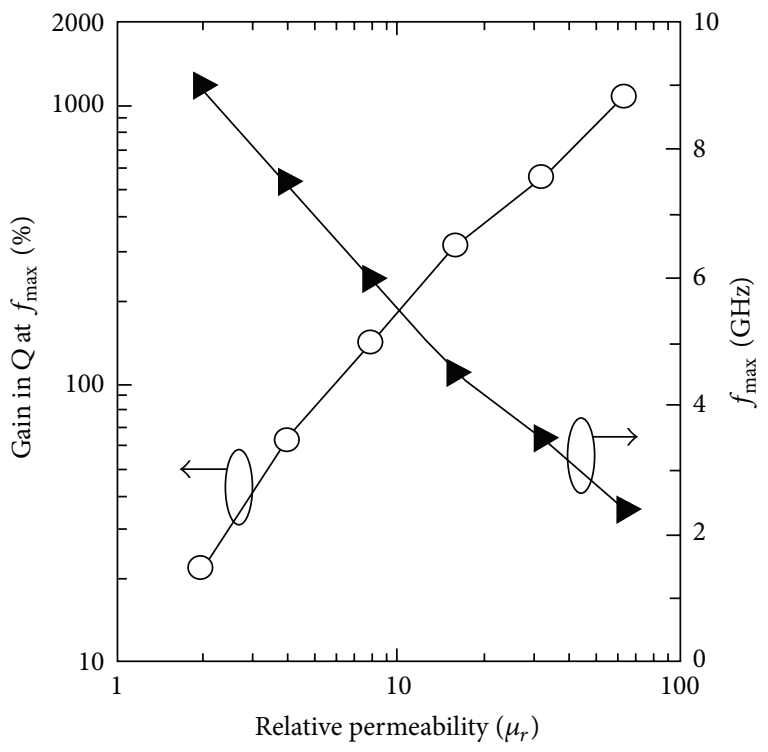

(b)

FIgURE 13: Performance comparison of multilayer and solenoid inductors of structures (e)-(h) with different relative permeability.

inductors increase from 1 to 100 , the improvement of $L$ and $Q$ has an increasing trend, while the $f_{\max }$ have an opposite trend.

The above simulations consider the ferrite as the ideal magnetic material without magnetic loss $\left(\mu^{\prime \prime}=10\right)$. In the ideal situation, the gain in $L$ of structure $B$ to (i) increases greatly with the ferrite filling degree increasing, as shown in Figure 14(a). However, when the $\mu^{\prime \prime}$ is considered, the gain in $Q$ of structure B to (i) reduces, as shown in Figure 14(b) [51]. 


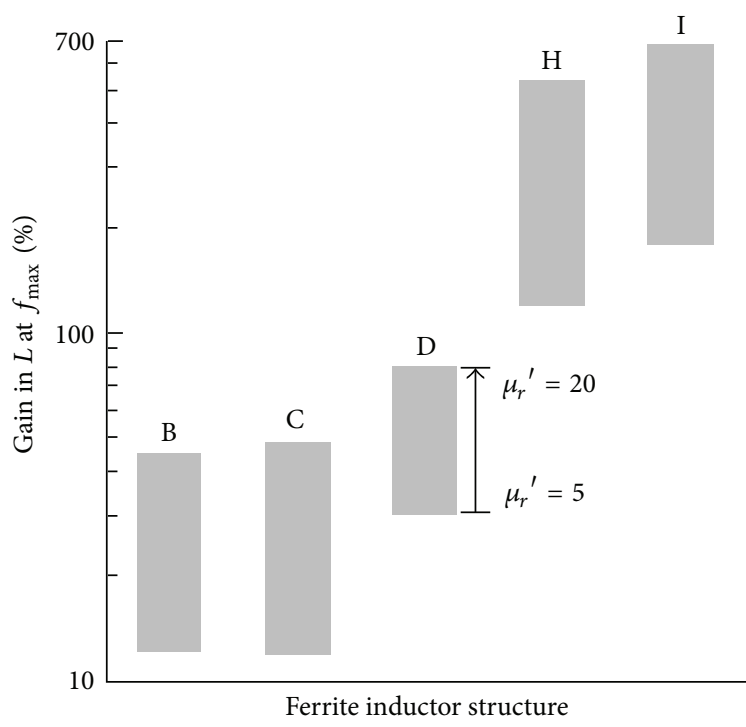

(a)

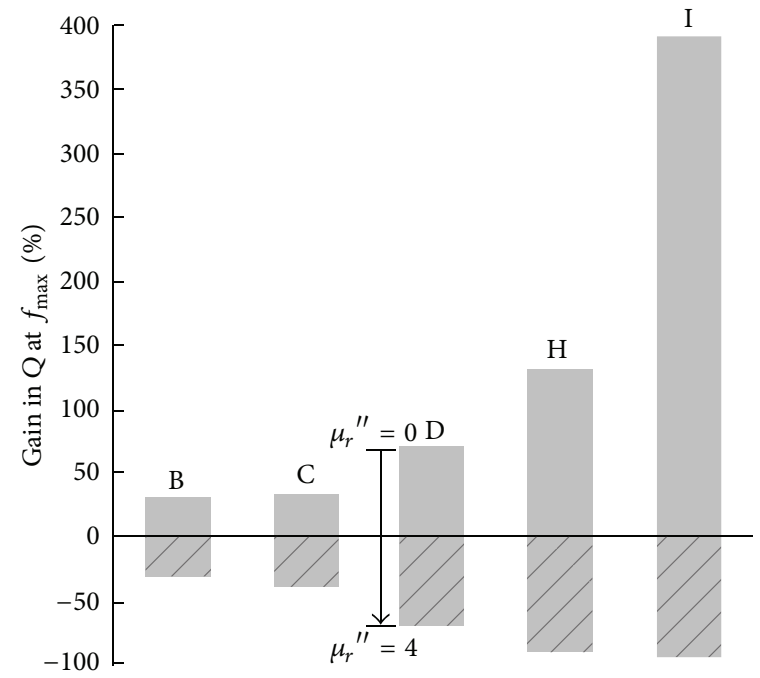

Ferrite inductor structure

(b)

FIGURE 14: (a) The $L$ gain of different inductor structures with ideal ferrite ( $\left.\mu_{r}^{\prime}: 5-20\right)$; (b) the $Q$ gain of different inductor structures with ferrite with loss $\left(\mu_{r}^{\prime \prime}: 0-4\right)$.

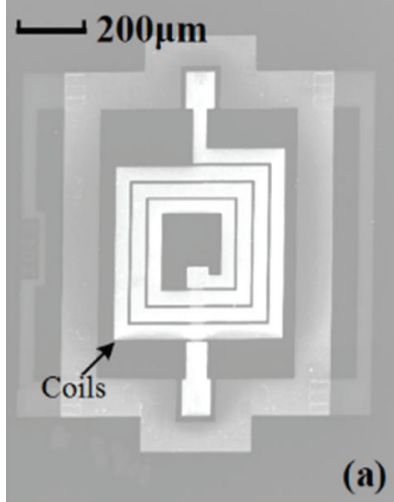

(a)

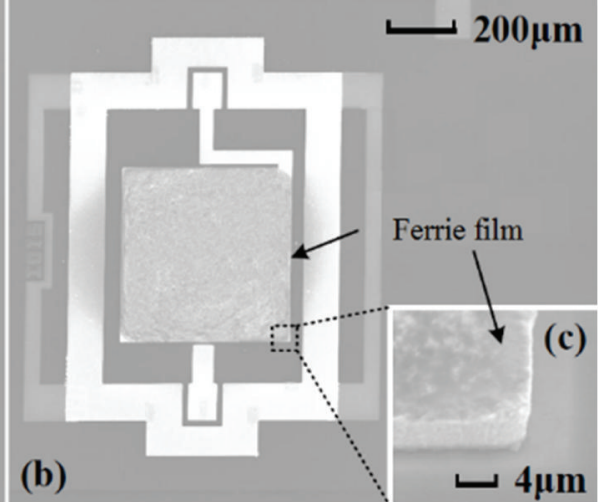

(b) (c)

FIGURE 15: Single layer on-chip inductor (a) without ferrite and (b) with ferrite.

\section{Device Fabrication}

Ferrite-integrated on-chip inductors with various ferritefilling structures are fabricated with CMOS compatible process.

Figure 15 shows the fabricated single layer magnetic inductor with ferrite nanomaterial coated on top. The single layer inductor is first fabricated by MEMS process; then the area that will be filled with magnetic nanomaterial is etched to form a cavity. Through spin-coating method, the ferrite nanomaterial mixed in photoresist fill the cavity up, followed by photolithography and etching processes that define the patterning of the magnetic film.

Multilayer and solenoid magnetic inductors are shown in Figures 16 and 17. They are also fabricated by MEMS process. When the several metal layers are connected and form a whole device, etch the bottom bulk silicon to suspend the device. Through the inkjetting method, the ferrite nanomaterial is injected to the target area.

\section{Results and Discussion}

The performance of inductor samples is measured using Agilent 8722ES.

Figure 18 shows the measured $L$ and $Q$ of single layer inductor with ferrite nanomaterial. The single layer on-chip inductor shows good improvement when integrated with ferrite nanomaterial. The maximum inductance gains are $21 \%$ and $35 \%$ with $\mathrm{Co}_{2} \mathrm{Z}$ and $\mathrm{Ni}-\mathrm{Zn}-\mathrm{Cu}$, respectively, and the improvements are still effective even in $10 \mathrm{GHz}$ range. The Q's improvement can also reach to over $3 \mathrm{GHz}$, and the maximum gains are more than $100 \%$ and $160 \%$ with $\mathrm{Co}_{2} \mathrm{Z}$ and 


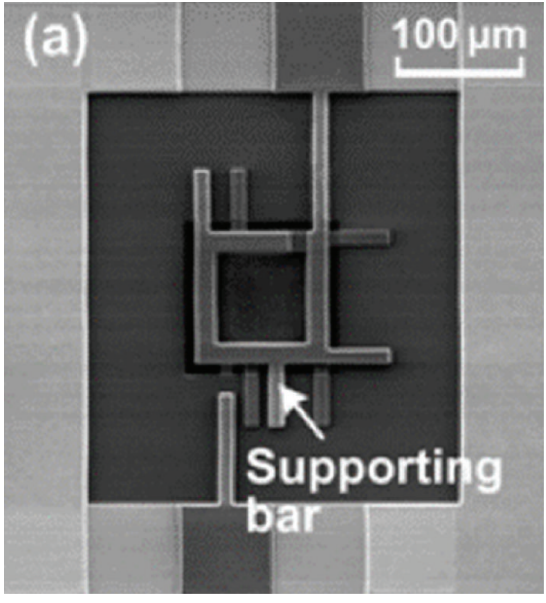

(a)

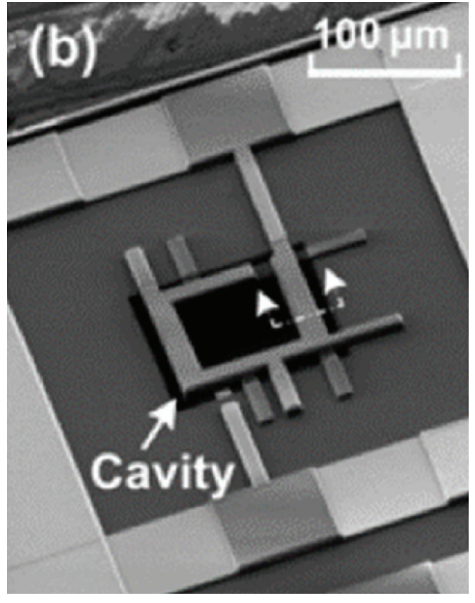

(b)

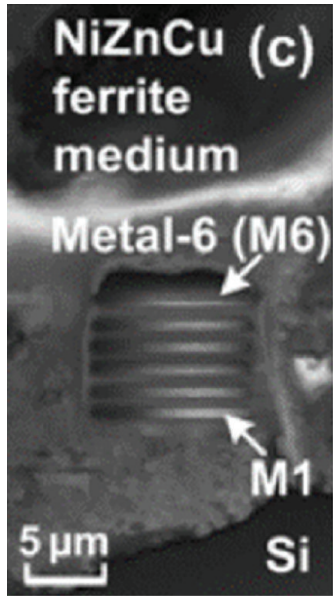

(c)

FIGURE 16: Multilayer on-chip inductor (a) and (b) without ferrite and (c) with ferrite.

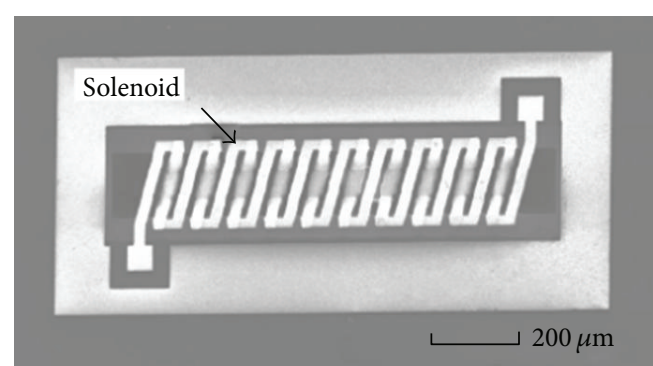

(a)

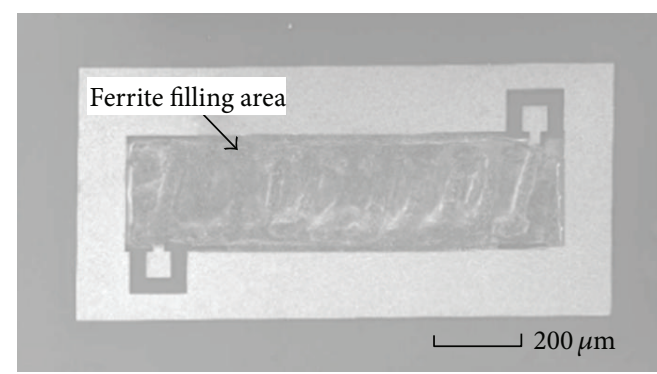

(b)

FIGURE 17: Solenoid structure on-chip inductor (a) without ferrite and (b) with ferrite fabricated by Shanghai Institute of Microsystem and Information Technology, Chinese Academy of Science.
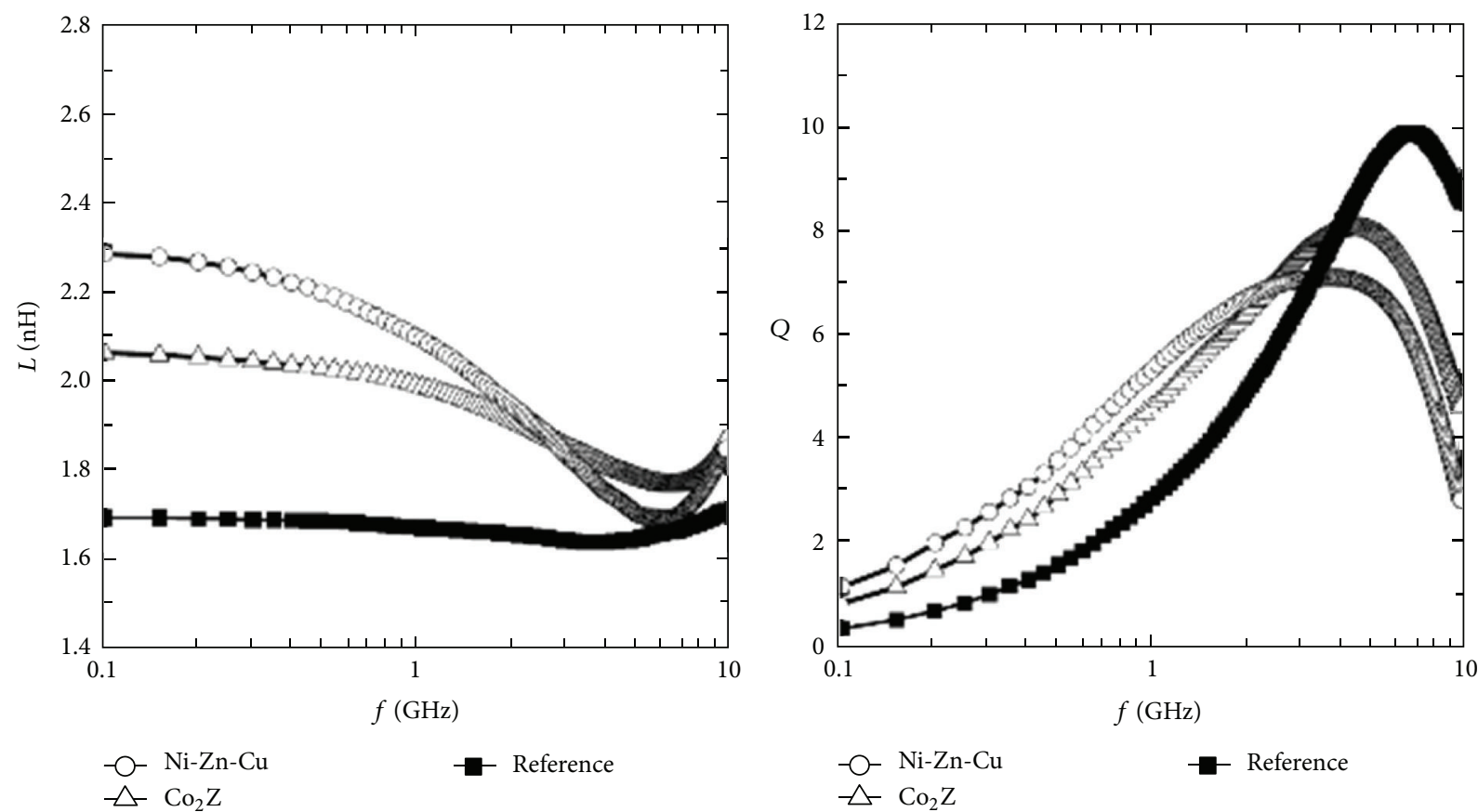

FIgURE 18: Measured $L$ and $Q$ of single layer inductor with ferrite nanomaterial fully filled. 

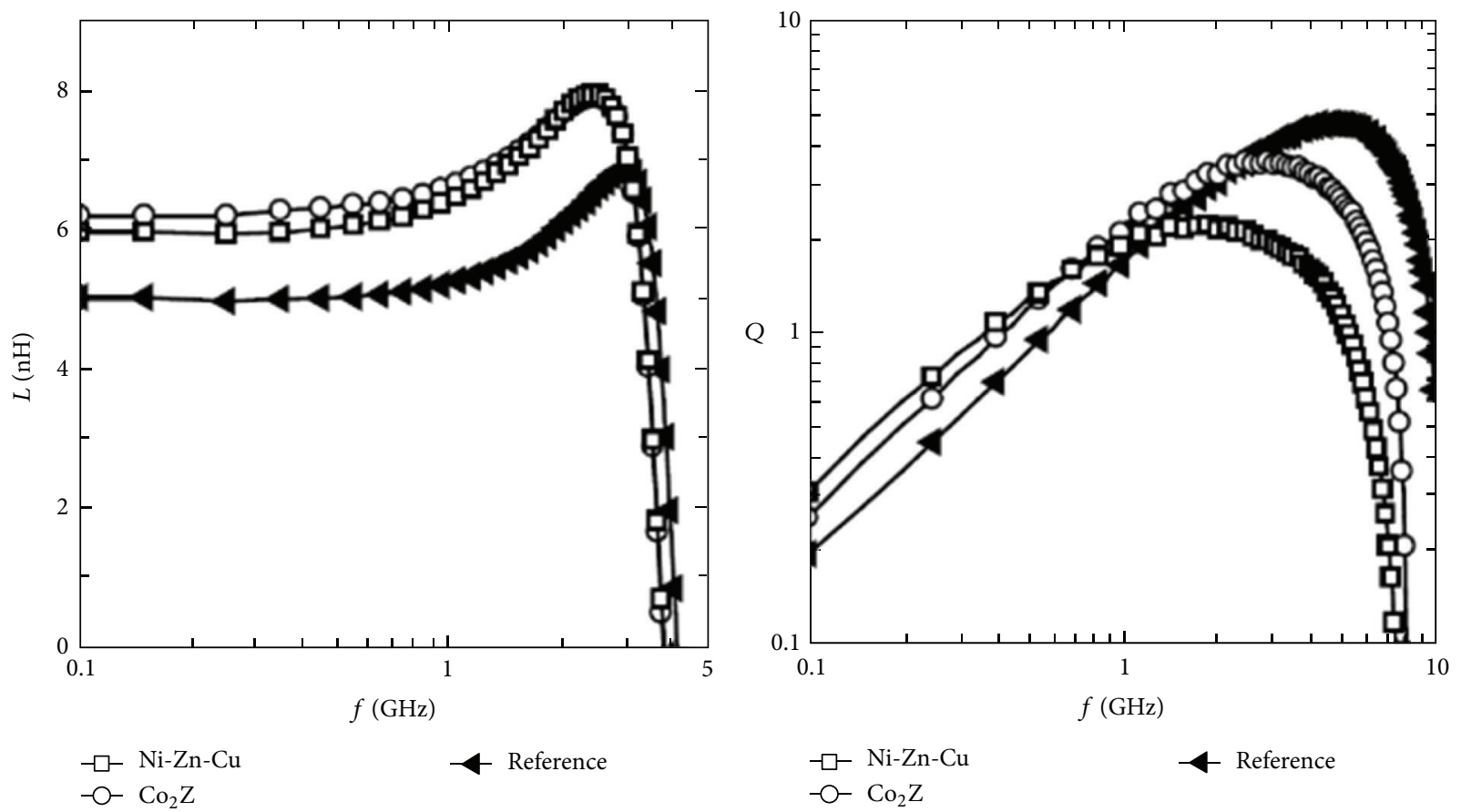

FIGURE 19: Measured $L$ and $Q$ of multilayer inductor with ferrite fully filled.
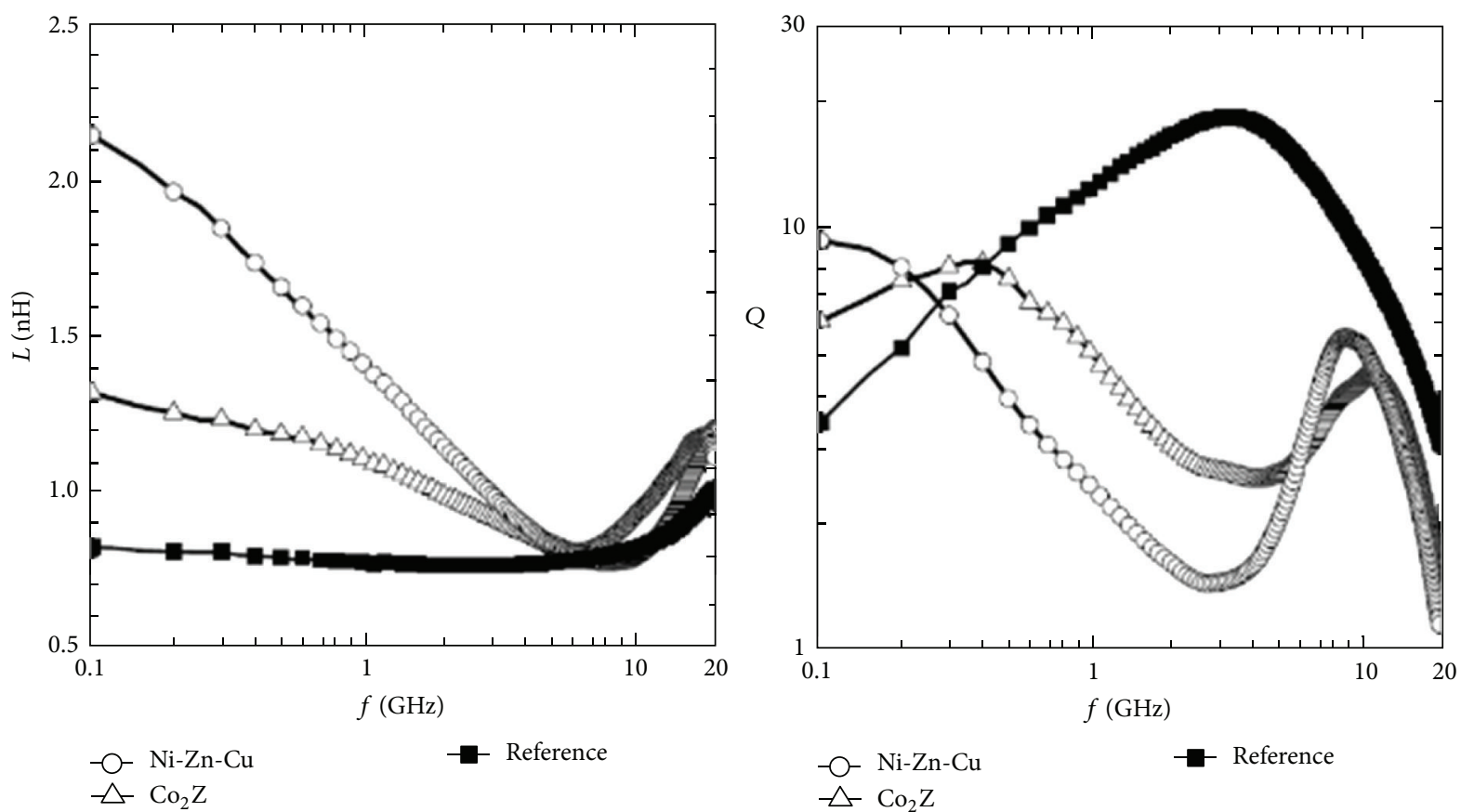

FIgURE 20: Measured $L$ and $Q$ of solenoid inductor with ferrite fully filled.

$\mathrm{Ni}-\mathrm{Zn}-\mathrm{Cu}$, respectively, which is competitive when compared with $[22,34,35,52]$.

Figure 19 shows measured $L$ and $Q$ of multilayer inductor with ferrite nanomaterial fully filled. The maximum inductance gains are $20 \%$ and $25 \%$, and the maximum gains of $Q$ are $40 \%$ and $50 \%$ with $\mathrm{Co}_{2} \mathrm{Z}$ and $\mathrm{Ni}-\mathrm{Zn}-\mathrm{Cu}$, respectively [53].
Figure 20 shows measured $L$ and $Q$ of solenoid inductor with ferrite nanomaterial fully filled. The $L$ improvement of solenoid structure is much larger than that of the two structures above, and the frequency range is more than $20 \mathrm{GHz}$. The maximum inductance gains are $63 \%$ and $168 \%$ with $\mathrm{Co}_{2} \mathrm{Z}$ and $\mathrm{Ni}-\mathrm{Zn}-\mathrm{Cu}$, respectively. While the $\mathrm{Q}$ decreases 
sharply, when it comes to several hundred megahertz. But the improvement in low frequency is impressive, and the $Q$ gain is $71 \%$ and $157 \%$ with $\mathrm{Co}_{2} \mathrm{Z}$ and $\mathrm{Ni}-\mathrm{Zn}-\mathrm{Cu}$ in $100 \mathrm{MHz}$, respectively.

After analyzing the measurement, we can conclude that with the enhancement of the degree of filling, the inductance of on-chip inductor increases abidingly, while the $Q$ factor reduces to a certain extent. The reason for this is due to the magnetic loss of ferrite, which is also already discussed in Figure 14. The magnetic loss effect strengthens with frequency, which causes the decline of peak value of $Q$ in high frequency. Besides, the two kinds of magnetic materials have a different magnetic spectrum with different relative permeability and magnetic loss, which is the reason for different performance improvement.

\section{Conclusion}

The ferrite nanomaterial is proposed for the application of RF range on-chip inductor to solve the problem of poor $Q$ and large area. An equivalent model of on-chip magnetic inductors is introduced. Several structures of on-chip magnetic inductors are designed and simulated. Ferrite nanomaterial is prepared and, CMOS-compatible process is explored. The fabricated ferrite-integrated on-chip inductor samples show obvious performance improvement in $\mathrm{GHz}$ range and are very promising to apply to RF circuit systems.

\section{Authors' Contribution}

Hua-Lin Cai and Jing Zhan contributed to the paper equally, and their orders are decided by coin.

\section{Acknowledgments}

This work was supported by the National Science Foundation (61025021, 60936002, and 61020106006) and National Key Project of Science and Technology (2011ZX02403-002) of China.

\section{References}

[1] J. N. Burghartz and B. Rejaei, "On the design of RF spiral inductors on silicon," IEEE Transactions on Electron Devices, vol. 50, no. 3, pp. 718-729, 2003.

[2] H.-S. Kim, D. Zheng, A. J. Becker, and Y.-H. Xie, "Spiral inductors on $\mathrm{Si} / \mathrm{p}$ + substrates with resonant frequency of 20 GHz," IEEE Electron Device Letters, vol. 22, no. 6, pp. 275-277, 2001.

[3] X. Huo, P. C. H. Chan, K. J. Chen, and H. C. Luong, "A physical model for on-chip spiral inductors with accurate substrate modeling," IEEE Transactions on Electron Devices, vol. 53, no. 12, pp. 2942-2948, 2006.

[4] X. Huo, K. J. Chen, and P. C. H. Chan, "Silicon-based high-Q inductors incorporating electroplated copper and low-K BCB dielectric," IEEE Electron Device Letters, vol. 23, no. 9, pp. 520522,2002

[5] A. Farcy, J.-F. Carpentier, M. Thomas, J. Torres, and P. Ancey, "Integration of high-performance RF passive modules (MIM capacitors and inductors) in advanced BEOL," Microelectronic Engineering, vol. 85, no. 10, pp. 1940-1946, 2008.

[6] C. S. Lin, Y. K. Fang, S. F. Chen et al., "A deep submicrometer CMOS process compatible high- $Q$ air-gap solenoid inductor with laterally laid structure," IEEE Electron Device Letters, vol. 26, no. 3, pp. 160-162, 2005.

[7] C.-H. Chen, Y.-K. Fang, C.-W. Yang, and C. S. Tang, "A deep submicron CMOS process compatible suspending high- $Q$ inductor," IEEE Electron Device Letters, vol. 22, no. 11, pp. 522523, 2001.

[8] J.-B. Yoon, Y.-S. Choi, B.-I. Kim, Y. Eo, and E. Yoon, "CMOScompatible surface-micromachined suspended-spiral inductors for multi-GHz silicon RF ICs," IEEE Electron Device Letters, vol. 23, no. 10, pp. 591-593, 2002.

[9] M.-C. Hsieh, Y.-K. Fang, C.-H. Chen, S.-M. Chen, and W.K. Yeh, "Design and fabrication of deep submicron CMOS technology compatible suspended high-Q spiral inductors," IEEE Transactions on Electron Devices, vol. 51, no. 3, pp. 324331, 2004.

[10] M. Tang, H. Y. Li, Q. X. Zhang et al., "High-Q on-chip inductors using extremely thick silicon dioxide and copper-damascene technology," Electronics Letters, vol. 44, no. 3, pp. 241-242, 2008.

[11] F. M. Rotella and J. Zachan, "Modeling and optimization of inductors with patterned ground shields for a high performance fully integrated switched tuning VCO," in Proceedings of IEEE Custom Integrated Circuits Conference, pp. 221-224, May 2002.

[12] Z. Zhang and X. Liao, "Micromachined GaAs MMIC-based spiral inductors with metal shores and patterned ground shields," IEEE Sensors Journal, vol. 12, no. 6, pp. 1853-1860, 2012.

[13] K. Chong, Y.-H. Xie, K.-W. Yu, D. Huang, and M.-C. F. Chang, "High-performance inductors integrated on porous silicon," IEEE Electron Device Letters, vol. 26, no. 2, pp. 93-95, 2005.

[14] X. Huo, G.-W. Xiao, K. J. Chen, and P. C. H. Chan, "Siliconon-organic integration of a $2.4 \mathrm{GHz} \mathrm{VCO}$ using high $\mathrm{Q}$ copper inductors and solder-bumped flip chip technology," in Proceedings of the IEEE Custom Integrated Circuits Conference, pp. 537540, September 2003.

[15] A. Nieuwoudt and Y. Massoud, "Predicting the performance of low-loss on-chip inductors realized using carbon nanotube bundles," IEEE Transactions on Electron Devices, vol. 55, no. 1, pp. 298-312, 2008.

[16] X. Huo, K. J. Chen, and P. C. H. Chan, "Silicon-based high-Q inductors incorporating electroplated copper and low-K BCB dielectric," IEEE Electron Device Letters, vol. 23, no. 9, pp. 520522, 2002.

[17] J. Du, W. Zou, and X. Zou, "An accurate physics-based method for calculating DC inductance of on-chip square multi-layer inductors," in Proceedings of the 9th IEEE International Conference on ASIC (ASICON '11), pp. 775-7778, 2011.

[18] X. Xiangming, L. Pingliang, C. Miao, and H. Bo, "Design of novel high- $Q$-factor multipath stacked on-chip spiral inductors," IEEE Transactions on Electron Devices, vol. 59, no. 8, pp. 2011-2018, 2012.

[19] D. S. Gardner, G. Schrom, F. Paillet, B. Jamieson, T. Karnik, and S. Borkar, "Review of on-chip inductor structures with magnetic films," IEEE Transactions on Magnetics, vol. 45, no. 10, pp. 47604766, 2009.

[20] V. Korenivski, "GHz magnetic film inductors," Journal of Magnetism and Magnetic Materials, vol. 215-216, pp. 800-806, 2000.

[21] Y. Zhuang, M. Vroubel, B. Rejaei, and J. N. Burghartz, “Thin film magnetic materials for RFIC passives," in Proceedings of IEEE 
Bipolar/BiCMOS Circuits and Technology Meeting (BCTM '05), pp. 26-32, October 2005.

[22] W. Xu, S. Sinha, T. Dastagir et al., "Performance enhancement of on-chip inductors with permalloy magnetic rings," IEEE Electron Device Letters, vol. 32, no. 1, pp. 69-71, 2011.

[23] H. Matsumoto, A. Urata, Y. Yamada, and A. Inoue, "Novel $\mathrm{Fe}(97-\mathrm{x}-\mathrm{y}) \mathrm{PxByNb} 2 \mathrm{Cr}$ l glassy alloys with high magnetization and low loss characteristics for inductor core materials," IEEE Transactions on Magnetics, vol. 46, no. 2, pp. 373-376, 2010.

[24] L. Li, D. Lee, S. X. Wang et al., "High frequency responses of granular magnetic material $\mathrm{CoFeHfO}$ and amorphous material CoZrTa," in Proceedings of IEEE International Magnetics Conference (INTERMAG '06), p. 54, May 2006.

[25] J. F. Godsell, S. Kulkarni, T. O’Donnell, and S. Roy, "Precessional dynamics of Ni45 Fe55 thin films for ultrahigh frequency integrated magnetics," Journal of Applied Physics, vol. 107, no. 3, Article ID 033907, 2010.

[26] C. Yang, K. Koh, X. Zhu, and L. Lin, "On-chip RF inductors with magnetic nano particles medium," in Proceedings of the 16th International Solid-State Sensors, Actuators and Microsystems Conference (TRANSDUCERS '11), pp. 2801-2804, June 2011.

[27] K. Koh, J. Park, J. Park, X. Zhu, and L. Lin, "Core-shell magnetic nanoparticles for on-chip RF inductors," in Proceedings of the 26th IEEE International Conference on Micro Electro Mechanical Systems (MEMS '13), pp. 465-468, 2013.

[28] B. Orlando, A.-S. Royet, and B. Viala, "Fast analysis of proximity effects in integrated inductors with high-permeability magnetic material," IEEE Transactions on Magnetics, vol. 42, no. 10, pp. 3371-3373, 2006.

[29] M. Yamaguchi, M. Baba, K. Suezawa et al., "Improved RF integrated magnetic thin-film inductors by means of micro slits and surface planarization techniques," IEEE Transactions on Magnetics, vol. 36, no. 5, pp. 3495-3498, 2000.

[30] M. Yamaguchi, N. Sato, and Y. Endo, "Skin effect suppression in multilayer thin-film spiral inductor taking advantage of negative permeability of magnetic film beyond FMR frequency," in Proceedings of European Microwave Conference (EuMC '10), pp. 1182-1185, September 2010.

[31] D. Linien, X. Sun, G. Carchon et al., "Low-power voltagecontrolled oscillators in 90-nm CMOS using high-quality thinfilm postprocessed inductors," IEEE Journal of Solid-State Circuits, vol. 40, no. 9, pp. 1922-1929, 2005.

[32] T. Dastagir, W. Xu, S. Sinha, H. Wu, Y. Cao, and H. Yu, “Tuning the permeability of permalloy films for on-chip inductor applications," Applied Physics Letters, vol. 97, no. 16, Article ID $162506,2010$.

[33] Y. Zhuang, B. Rejaei, E. Boellaard, M. Vroubel, and J. N. Burghartz, "Integrated solenoid inductors with patterned, sputter-deposited $\mathrm{Cr} / \mathrm{Fe}_{10} \mathrm{Co}_{90} / \mathrm{Cr}$ ferromagnetic cores," IEEE Electron Device Letters, vol. 24, no. 4, pp. 224-226, 2003.

[34] D. S. Gardner, G. Schrom, P. Hazucha et al., "Integrated on-chip inductors with magnetic films," in Proceedings of International Electron Devices Meeting (IEDM '06), pp. 1-4, December 2006.

[35] C. Yang, T.-L. Ren, F. Liu et al., "On-chip integrated inductors with ferrite thin-films for RF IC," in Proceedings of International Electron Devices Meeting (IEDM '06), pp. 1-4, December 2006.

[36] T. Maruyama, Y. Obinata, M. Sonehara, K. Ikeda, and T. Sato, "Increase of Q-factor of RF magnetic thin film inductor by introducing slit-patterned magnetic thin film and multilineconductor spiral coil," IEEE Transactions on Magnetics, vol. 47, no. 10, pp. 3196-3199, 2011.
[37] D. J. Sadler, S. Gupta, and C. H. Ahn, "Micromachined spiral inductors using UV-LIGA techniques," IEEE Transactions on Magnetics, vol. 37, no. 4, pp. 2897-2899, 2001.

[38] C. Yang, F. Liu, X. Wang et al., "Investigation of on-chip softferrite-integrated inductors for RF ICs-part I: design and simulation," IEEE Transactions on Electron Devices, vol. 56, no. 12, pp. 3133-3140, 2009.

[39] C. Yang, F. Liu, X. Wang et al., "Investigation of on-chip softferrite-integrated inductors for RF ICs-part II: experiments," IEEE Transactions on Electron Devices, vol. 56, no. 12, pp. 31413148, 2009.

[40] M. Yamaguchi, S. Bae, K. H. Kim, K. Tan, T. Kusumi, and K. Yamakawa, "Ferromagnetic RF integrated inductor with closed magnetic circuit structure," in Proceedings of IEEE MTTS International Microwave Symposium, pp. 351-354, June 2005.

[41] M. Yamaguchi, K. Hyeon Kim, and S. Ikedaa, "Soft magnetic materials application in the RF range," Journal of Magnetism and Magnetic Materials, vol. 304, no. 2, pp. 208-213, 2006.

[42] A. T. Raghavender, S. E. Shirsath, and K. Vijaya Kumar, "Synthesis and study of nanocrystalline $\mathrm{Ni}-\mathrm{Cu}-\mathrm{Zn}$ ferrites prepared by oxalate based precursor method," Journal of Alloys and Compounds, vol. 509, no. 25, pp. 7004-7008, 2011.

[43] J. Mürbe and J. Töpfer, "Ni-Cu-Zn ferrites for low temperature firing: I. Ferrite composition and its effect on sintering behavior and permeability," Journal of Electroceramics, vol. 15, no. 3, pp. 215-221, 2005.

[44] M. Hashim, Alimuddin, S. E. Shirsath et al., "Preparation and characterization chemistry of nano-crystalline $\mathrm{Ni}-\mathrm{Cu}-\mathrm{Zn}$ ferrite," Journal of Alloys and Compounds, vol. 549, pp. 348-357, 2013.

[45] I.-G. Chen, S.-H. Hsu, and Y. H. Chang, "Preparation and magnetic properties of $\mathrm{Ba}-\mathrm{Co}_{2} \mathrm{Z}$ and $\mathrm{Sr}-\mathrm{Zn}_{2} \mathrm{Y}$ ferrites," Journal of Applied Physics, vol. 87, no. 9, pp. 6247-6249, 2000.

[46] R. Chang and W. Zhang, "A comprehensive linear-regressionbased procedure for inductor parameter extraction," in Proceedings of International Symposium on VLSI Design, Automation and Test (VLSI-DAT '09), pp. 287-290, April 2009.

[47] Y. Cao, R. A. Groves, X. Huang et al., "Frequency-independent equivalent-circuit model for on-chip spiral inductors," IEEE Journal of Solid-State Circuits, vol. 38, no. 3, pp. 419-426, 2003.

[48] O. H. Murphy, K. G. McCarthy, C. J. P. Delabie, A. C. Murphy, and P. J. Murphy, "Design of multiple-metal stacked inductors incorporating an extended physical model," IEEE Transactions on Microwave Theory and Techniques, vol. 53, no. 6, pp. 20632072, 2005.

[49] C. Wang, H. Liao, C. Li et al., "A wideband redictive "double$\pi$ " equivalent-circuit model for on-chip spiral inductors," IEEE Transactions on Electron Devices, vol. 56, no. 4, pp. 609-619, 2009.

[50] W. Tao and G. P. Carman, "Ultra-low power electrically reconfigurable magnetoelectric microwave devices," Journal of Applied Physics, vol. 112, no. 7, Article ID 073915, 6 pages, 2012.

[51] M. Yamaguchi, Y. Endo, N. Sato, and A. Ludwig, "Overview of RF high-permeability ferromagnetic thin films and its application to a new ferromagnetic/conductive multilayer to suppress skin effect in RF on-chip conductors," in Proceedings of Microwave Integrated Circuits Conference (EuMIC '11), pp. 7780, October 2011. 
[52] W. Xu, S. Sinha, F. Pan, T. Dastagir, and Y. Cao, "Improved frequency response of on-chip inductors with patterned magnetic dots," IEEE Electron Device Letters, vol. 31, no. 3, pp. 207-209, 2010.

[53] J. Zhan, T. Ren, C. Yang, Y. Yang, L. Liu, and A. Wang, "Design of magnetic RF inductor in CMOS," Tsinghua Science and Technology, vol. 17, no. 1, pp. 78-83, 2012. 

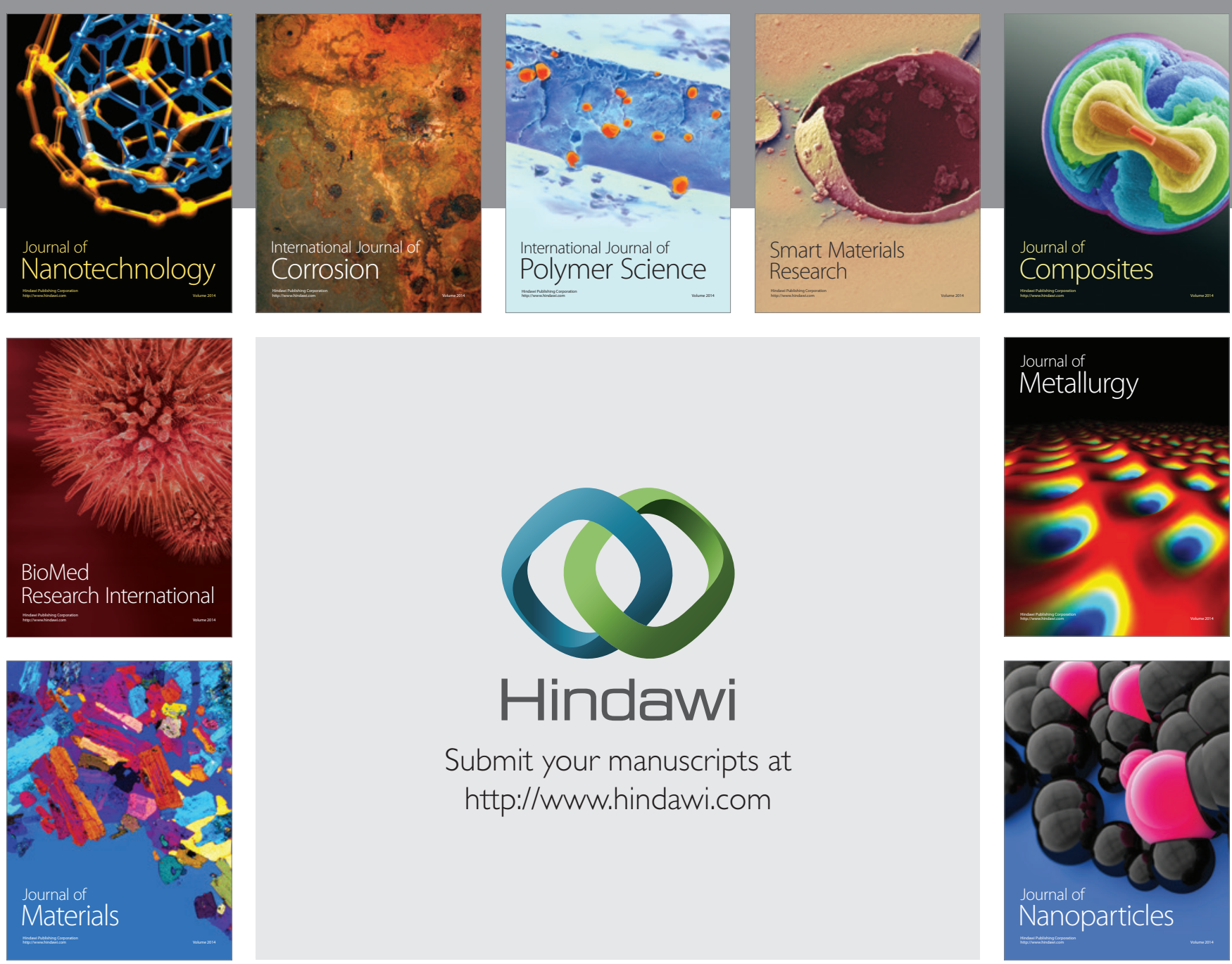

Submit your manuscripts at http://www.hindawi.com
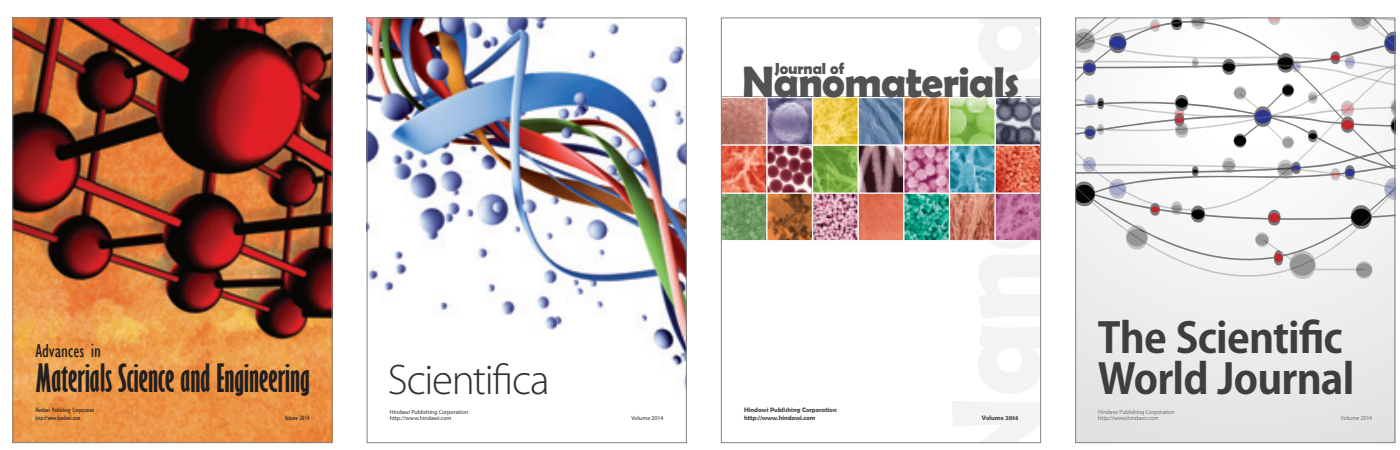

\section{The Scientific World Journal}
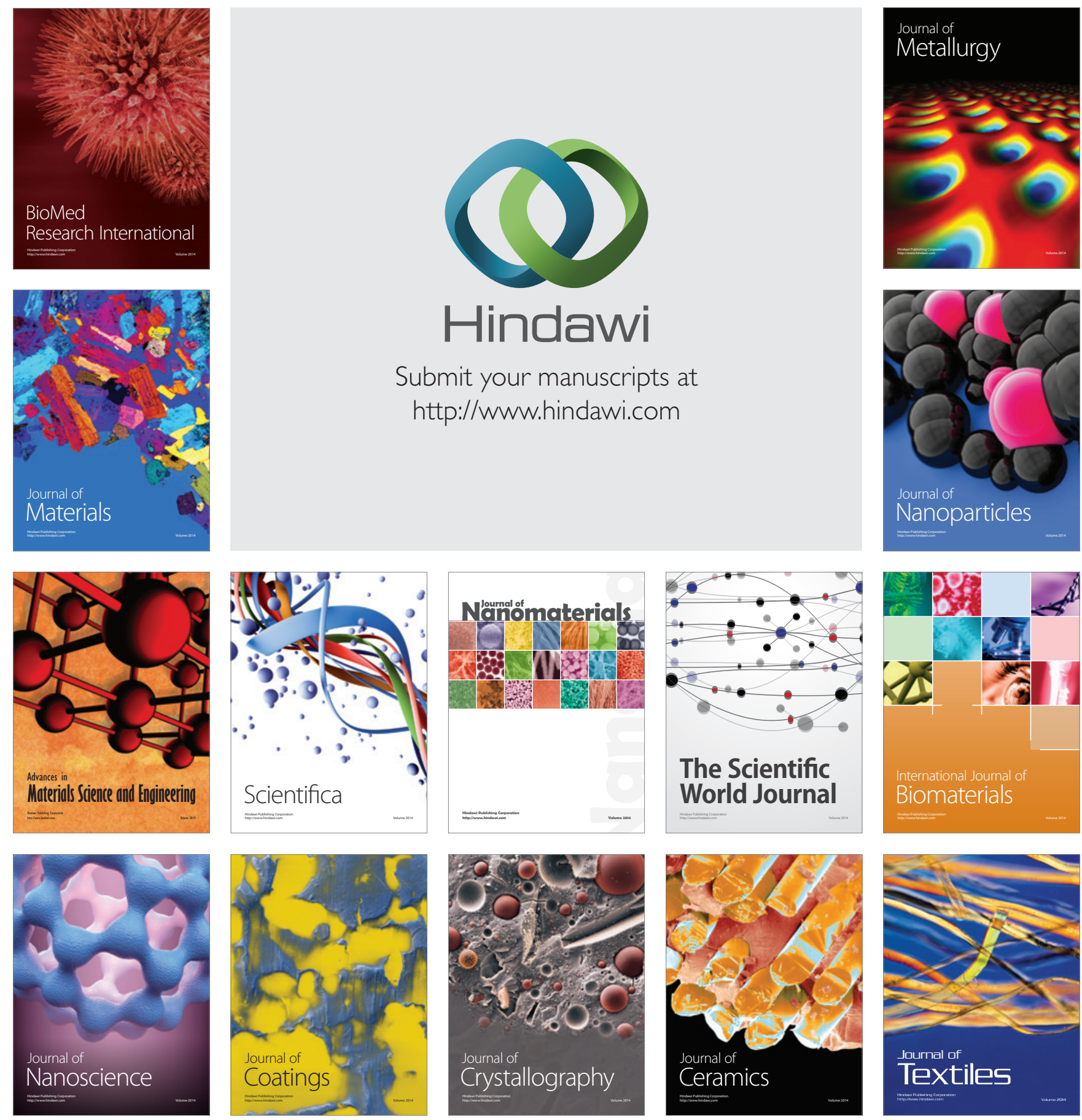